\title{
HIGH HEPATITIS B AND LOW HEPATITIS C PREVALENCE IN ROMA POPULATION IN EASTERN SLOVAKIA
}

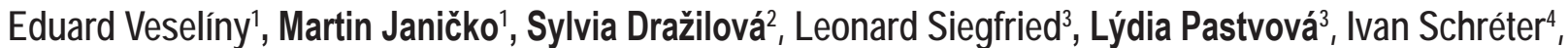 \\ Pavol Kristian ${ }^{4}$, Ladislav Virág ${ }^{4}$, Pavol Jarčuška4 ${ }^{4}$, Ivana Valková4, Katarína Cáriková4, Gabriela Senajová ${ }^{1}$, Ján \\ Fedačko ${ }^{1}$, Daniel Pella ${ }^{1}$, Mária Mareková5 ${ }^{5}$, Andrea Madarasová Gecková6, ${ }^{6}$, Peter Jarčuška ${ }^{1}$; HepaMeta Team* \\ ${ }^{1} 1$ st Department of Internal Medicine, P. J. Šafárik University in Košice, Faculty of Medicine and L. Pasteur University Hospital, Košice, Slovakia \\ ${ }^{2}$ Department of Internal Medicine, Poprad Hospital, Poprad, Slovakia \\ ${ }^{3}$ Department of Medical Microbiology, P. J. Šafárik University in Košice, Faculty of Medicine and L. Pasteur University Hospital, Košice, Slovakia \\ ${ }^{4}$ Department of Infectious Diseases, P. J. Šafárik University in Košice, Faculty of Medicine and L. Pasteur University Hospital, Košice, Slovakia \\ ${ }^{5}$ Department of Medical and Clinical Biochemistry and LABMED, Faculty of Medicine, P. J. Šafárik University in Košice, Košice, Slovakia \\ ${ }^{6}$ Health Psychology Unit, Department of Public Health, Faculty of Medicine, P. J. Šafárik University in Košice, Košice, Slovakia \\ ${ }^{7}$ Olomouc University Social Health Institute, Palacký University in Olomouc, Olomouc, Czech Republic
}

\section{SUMMARY}

Background: Viral hepatitis B and C prevalence in the Roma population of eastern Slovakia is largely unknown. This study aimed to explore the prevalence and associated risk factors of chronic viral hepatitis B and C among Roma living in segregated communities in eastern Slovakia.

Methods: Data from the cross-sectional HepaMeta study conducted in Slovakia in 2011 among Roma living in rural communities were used. Participants were tested for the presence of HBsAg, anti-HBc IgG and anti-HCV. The risk factors were assessed mainly via a structured questionnaire/interview.

Results: Altogether 452 Roma were screened, and 11 were excluded due to missing data. A total of 441 patients were included (mean age $34.7 \pm 9.14$ years; $35.2 \%$ men). $12.5 \%$ of participants were $\mathrm{HBsAg}$ positive, $40.4 \%$ anti-HBc IgG positive while negative for $\mathrm{HBsAg}$ and $47.2 \%$ of participants were negative for all serological markers of hepatitis B. Hepatitis C prevalence was very low (0.7\%), while 2 out of 3 anti-HCV positive participants were coinfected with hepatitis B. Risk factors for hepatitis B infection were male sex, higher age, tattoo, and previous imprisonment. No difference was found in intravenous drug use, blood transfusions and sexual behaviour.

Conclusion: More than half of the Roma residing in eastern Slovakia have been infected at one point in life with the hepatitis B virus, and $12.5 \%$ are HBsAg positive. Hepatitis $\mathrm{C}$ prevalence is very low, which is probably due to very low intravenous drug use.

Key words: hepatitis B prevalence, hepatitis C prevalence, Roma population, tattoo, imprisonment, sexual behaviour

Address for correspondence: Peter Jarčuška, 1st Department of Internal Medicine, P. J. Šafárik University, Faculty of Medicine and L. Pasteur University Hospital, Tr. SNP 1, 04011 Košice, Slovakia. E-mail: petjarc@yahoo.com

\section{INTRODUCTION}

Chronic viral hepatitis B and C are the most common causes of liver cirrhosis worldwide (1). More than 2 billion people acquire hepatitis B infection during their lifetime. Overall, 350-400 million people are infected with the hepatitis B virus, about 125 million of whom are Chinese (2). The prevalence of hepatitis C infection is about $3 \%$, which represents more than 200 million people (3).

Possible routes of transmission of hepatitis B and C are either vertical, from mother to child during birth, or horizontal via contact with contaminated blood or sexual intercourse. Probably the most common route of infection with hepatitis B is sexual intercourse. Regular sexual intercourse with an infected partner,

\footnotetext{
*HepaMeta Team members are listed in Appendix
}

promiscuity and homosexuality constitute particularly high risks. The risk for hepatitis B transmission among homosexuals rises with anal intercourse and the length of the period of sexual activity. About $75 \%$ of homosexual males were infected after 5 years of regular sexual intercourse (4). Transmission risk factors are similar for heterosexual men and women. Thirty-nine percent of all hepatitis B infections in the United States are transmitted via heterosexual intercourse and $24 \%$ via homosexual intercourse between men (5). The risk of hepatitis $\mathrm{C}$ transmission by sexual intercourse is relatively low compared with hepatitis B (6).

The hepatitis $\mathrm{B}$ and $\mathrm{C}$ virus is blood-borne, thus the following procedures are particularly dangerous: blood and blood-product transfusion; injury with a needle or contact with blood of infected or a presumably infected person; surgery and mini-invasive surgery; intravenous drug use; tattoo or piercing; haemodialysis; manicure and pedicure; use of the razor or toothbrush of an infected person $(6,7)$. 
Chronic hepatitis B and C can progress to liver cirrhosis and hepatocellular carcinoma. Hepatitis B carriers are at risk of hepatocellular carcinoma even without the development of liver cirrhosis (7). More than 1 million people die each year because of liver failure or hepatocellular carcinoma directly associated with hepatitis B (8).

The Roma population constitutes a specific minority which differs greatly from the majority population in terms of cultural stereotypes, lifestyle and socioeconomic status, probably due to their origin. Indeed, the origin of the Roma has been traced to North East India (9); therefore, the prevalence of hepatitis B would probably be higher than in the majority population.

The aim of this study was to explore the prevalence of hepatitis $\mathrm{B}$ and $\mathrm{C}$ among young Roma in Roma communities in eastern Slovakia and to analyse selected risk factors for hepatitis B and C infection.

\section{MATERIALS AND METHODS}

Data from the cross-sectional HepaMeta study conducted in Slovakia in 2011 were used. This project aimed to map the prevalence of viral hepatitis $\mathrm{B} / \mathrm{C}$ and metabolic syndrome in the population living in eastern Slovakia including Roma settlements. In addition to the general methodology described in detail elsewhere (10), further paper-specific amendments to the methodology follow.

Only Roma participants $(n=452)$ were included in this analysis. Participants were considered to have active HBV infection if they were HBsAg positive. Patients with anti-HBc IgG or antiHBs antibodies positivity were considered to have had encountered $\mathrm{HBV}$ in the past or were vaccinated.

\section{Statistical Analysis}

Results are presented as a median (interquartile range) for continuous variables with nonparametric distribution or mean \pm standard deviation for data with parametric distribution and as percentages for categorical variables unless stated other- wise. Differences between the two groups of participants were tested using the Mann-Whitney U test. The chi-square test (with continuity correction if low expected counts) was utilised for categorical variables.

\section{RESULTS}

A total of 452 Roma were screened. Serology was not available for 11 participants, thus the final sample included 441 probands. Mean age of the study sample was $34.7 \pm 9.14$ years, and males accounted for $35.2 \%$.

\section{Hepatitis B}

HBsAg positivity was found in 55 (12.5\%) participants (95\% confidence interval 9.71-15.88). From the HBsAg negative patients, anti-HBc IgG positivity was found in 178 (40.4\%) participants, while 208 (47.2\%) participants were both HBsAg and anti-HBc IgG negative. For subsequent analysis, we divided the participants into three groups: HBsAg positive patients were considered to have active hepatitis B infection; HBsAg negative but anti-HBc IgG positive patients were considered to have resolved hepatitis $\mathrm{B}$ infection; and the third group consisted of patients negative for both HBsAg and anti-HBc IgG.

First we compared participants with active hepatitis B with participants negative for both HBsAg and anti-HBc IgG. Results are summarised in Table 1. We found that HBsAg-positive patients are older and have a greater proportion of males. Surprisingly, promiscuity, represented by the reported number of sexual partners, was not found to be significantly associated with hepatitis B. Therefore, we performed gender specific analysis of reported sexual partners (Fig. 1) and found out that men reported significantly more sexual partners than women. We also found that $20 \%$ of HBsAg-positive participants reported using a condom always or most of the time compared with $7.4 \%$ of HBsAg and anti-HBc IgG-negative participants. The whole-group analysis of relationship between condom use and number of sexual partners proved

Table 1. Comparison of imprisonment, drug use, blood transfusion, sexual behaviour, and tattoo procedure between HBsAgpositive and HBsAg, HBc IgG-negative participants

\begin{tabular}{|l|c|c|c|c|}
\hline & N & HBsAg positive & $\begin{array}{c}\text { HBsAg, HBc lgG } \\
\text { negative } \\
\mathbf{n}(\%)\end{array}$ & $\mathbf{p}$ \\
\hline Gender (male) & 263 & $28(50.9)$ & $64(30.8)$ & 0.005 \\
\hline Age (years) & 261 & $35.2(12.2)$ & $30.7(6.1)$ & 0.028 \\
\hline Imprisonment & 259 & $7(12.7)$ & $13(6.4)$ & $\mathrm{ns}$ \\
\hline Drugs total & 260 & $1(1.9)$ & $6(2.9)$ & $\mathrm{ns}$ \\
\hline Intravenous drugs & 258 & - & $1(0.5)$ & - \\
\hline$>$ 4 sexual partners & 255 & $8(14.5)$ & $28(14.0)$ & $\mathrm{ns}$ \\
\hline Sex for money & 256 & $2(3.6)$ & $5(2.5)$ & $\mathrm{ns}$ \\
\hline Used condom always or most of the time & 257 & $11(20.0)$ & $15(7.4)$ & 0.006 \\
\hline Tattoo total & 257 & $23(44.2)$ & $69(33.7)$ & $\mathrm{ns}$ \\
\hline Tattoo privately & 250 & $20(40.8)$ & $65(32.3)$ & $\mathrm{ns}$ \\
\hline Tattoo parlour & 172 & $3(9.4)$ & $4(2.9)$ & $\mathrm{ns}$ \\
\hline Blood transfusion & 250 & $8(14.8)$ & $33(13.8)$ & $\mathrm{ns}$ \\
\hline
\end{tabular}




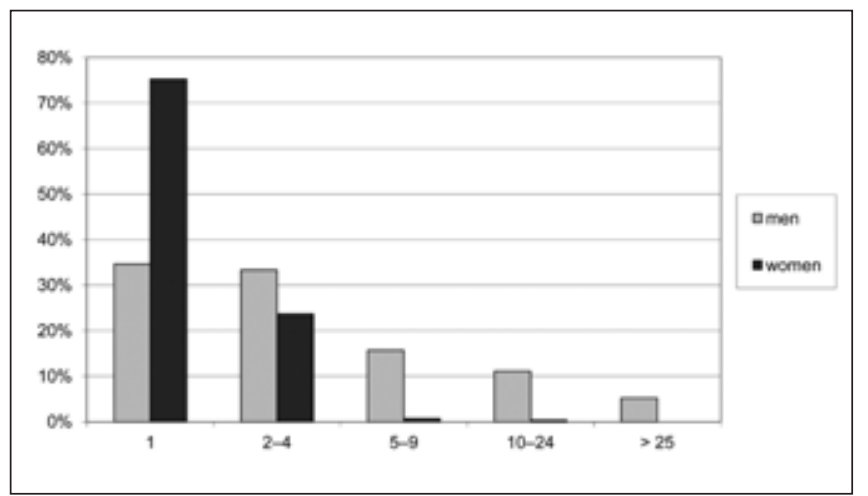

Fig. 1. Reported sexual partners by men and women; $p$ for difference $<0.001$.

that participants with more frequent condom use had also more sexual partners than participants who used condom rarely (Fig. 2).

Next we compared HBsAg-positive participants to participants who were HBsAg-negative but anti-HBc IgG positive (Table 2). In this case, anti-HBc IgG but HBsAg-negative participants were older than the HBsAg-positive participants, but there were still more men among the HBsAg-positive, and they used a condom more frequently.

In the third case we compared participants with resolved hepatitis B with participants who had never encountered this virus (Table 3). As expected, we found that HBc IgG positive participants were older, were more frequently imprisoned and more frequently tattooed. There was no difference in gender distribution. We have also obtained information about vaccination from participants' medical records. Only 15 participants (3.3\%) were vaccinated against hepatitis B in adulthood.

\section{Hepatitis C}

Anti-HCV positivity was found in only three participants (0.7\%). Two anti-HCV positive participants were also HBsAg

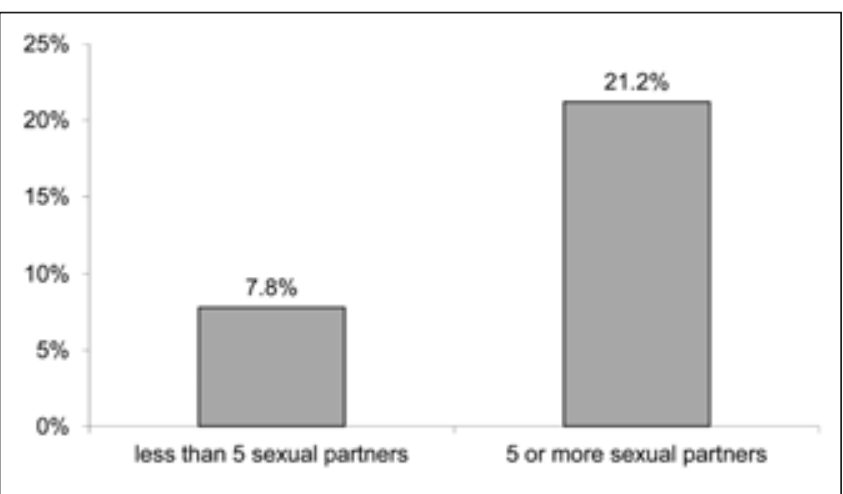

Fig. 2. Percentage of participants who reported using condom always/almost always by number of sexual partners; $p=0.002$.

positive. Due to the very low number of anti-HCV positive, no significant difference was observed in any parameter (Table 4).

\section{DISCUSSION}

Hepatitis B and C prevalence among the Roma of Central Europe has been very poorly explored. To this date we were able to find only one such paper in the MEDLINE database; it tried to map hepatitis B prevalence in the Hungarian Roma population. The authors tested 64 patients in the Dzumbuji region, 50 Roma and 14 people from the majority population. No patient had active hepatitis, $26 \%$ of Roma subjects and $28.6 \%$ of the majority subjects had come in contact with hepatitis B in the past (11).

In another study Greek authors tested 216 children (118 Roma) with a mean age of 9 years. Twenty-two percent of these Roma children had resolved hepatitis B infection and were anti-HBc positive, while $4 \%$ were HBsAg positive. No children from the majority group had HBsAg positivity (12).

We found out that the prevalence of active hepatitis $\mathrm{B}$ in the Roma population in segregated communities was $12.5 \%$, which is

Table 2. Comparison of imprisonment, drug use, blood transfusion, sexual behaviour, and tattoo procedure between HBsAgpositive and HBsAg-negative, but HBclgG-positive participants

\begin{tabular}{|l|c|c|c|c|}
\hline & $\mathbf{N}$ & $\begin{array}{c}\text { HBsAg positive } \\
\mathbf{n}(\%)\end{array}$ & $\begin{array}{c}\text { HBsAg negative } \\
\text { HBc lgG positive } \\
\mathbf{n}(\%)\end{array}$ & $\mathbf{p}$ \\
\hline Gender (male) & 233 & $28(50.9)$ & $63(35.4)$ & 0.039 \\
\hline Age (years) & 230 & $35.2(12.2)$ & $38.6(12.3)$ & 0.004 \\
\hline Imprisonment & 230 & $7(12.7)$ & $24(13.7)$ & $\mathrm{ns}$ \\
\hline Drugs total & 232 & $1(1.9)$ & $2(1.1)$ & $\mathrm{ns}$ \\
\hline Intravenous drugs & 226 & - & $1(0.6)$ & - \\
\hline$>4$ sexual partners & 226 & $8(14.5)$ & $15(8.8)$ & $\mathrm{ns}$ \\
\hline Sex for money & 227 & $2(3.6)$ & $6(3.5)$ & $\mathrm{ns}$ \\
\hline Used condom always or most of the time & 227 & $11(20.0)$ & $15(8.7)$ & 0.022 \\
\hline Tattoo total & 226 & $23(44.2)$ & $77(44.3)$ & $\mathrm{ns}$ \\
\hline Tattoo privately & 228 & $20(40.8)$ & $75(43.6)$ & $\mathrm{ns}$ \\
\hline Tattoo parlour & 131 & $3(9.4)$ & $2(2)$ & $\mathrm{ns}$ \\
\hline Blood transfusion & 221 & $8(14.8)$ & $27(16.2)$ & $\mathrm{ns}$ \\
\hline
\end{tabular}

*Median (interquartile range)

Significance tested by chi-square (with continuity correction if low expected counts) or Mann-Whitney $U$ test where appropriate ns non-significant difference $(p>0.05)$ 
Table 3. Comparison of imprisonment, drug use, blood transfusion, sexual behaviour, and tattoo procedure between HBc IgGpositive and HBc IgG-negative participants (only HBsAg negative)

\begin{tabular}{|l|c|c|c|c|}
\hline & $\mathbf{N}$ & $\begin{array}{c}\text { HBc IgG positive } \\
\mathbf{n}(\%)\end{array}$ & $\begin{array}{c}\text { HBc IgG negative } \\
\mathbf{n}(\%)\end{array}$ & $\mathbf{p}$ \\
\hline Gender (male) & 386 & $63(35.4)$ & $64(30.8)$ & $\mathrm{ns}$ \\
\hline Age (years) & 381 & $38.6(12.3)$ & $30.7(16.1)$ & $<0.001$ \\
\hline Imprisonment & 379 & $24(13.7)$ & $13(6.4)$ & 0.016 \\
\hline Drugs total & 384 & $2(1.1)$ & $6(2.9)$ & $\mathrm{ns}$ \\
\hline Intravenous drugs & 378 & $1(0.6)$ & $1(0.5)$ & $\mathrm{ns}$ \\
\hline$>4$ sexual partners & 371 & $15(8.8)$ & $28(14)$ & $\mathrm{ns}$ \\
\hline Sex for money & 373 & $6(3.5)$ & $5(2.5)$ & $\mathrm{ns}$ \\
\hline Used condom always or most of the time & 374 & $15(8.7)$ & $15(7.4)$ & $\mathrm{ns}$ \\
\hline Tattoo total & 379 & $77(44.3)$ & $69(33.7)$ & 0.035 \\
\hline Tattoo privately & 373 & $75(43.6)$ & $65(32.3)$ & 0.025 \\
\hline Tattoo parlour & 239 & $2(2.0)$ & $4(2.9)$ & $\mathrm{ns}$ \\
\hline Blood transfusion & 363 & $27(16.2)$ & $33(16.8)$ & $\mathrm{ns}$ \\
\hline
\end{tabular}

*Median (interquartile range)

Significance tested by chi-square (with continuity correction if low expected counts) or Mann-Whitney U test where appropriate ns non-significant difference $(p>0.05)$

Table 4. Comparison of imprisonment, drug use, blood transfusion, sexual behaviour, and tattoo procedure between anti-HCVpositive and negative participants

\begin{tabular}{|l|c|c|c|}
\hline & N & $\begin{array}{c}\text { Anti-HCV positive } \\
\mathbf{n}(\%)\end{array}$ & $\begin{array}{c}\text { Anti-HCV negative } \\
\mathbf{n}(\%)\end{array}$ \\
\hline Gender (males) & 441 & $2(66.7)$ & $153(34.9)$ \\
\hline Age (years) & 436 & $23.5(\mathrm{~N} / \mathrm{A})$ & $35.5(15.29)$ \\
\hline Imprisonment & 434 & - & $44(10.2)$ \\
\hline Drugs total & 438 & - & $9(2.1)$ \\
\hline Intravenous drugs & 431 & $1(33.3)$ & $2(0.5)$ \\
\hline$>4$ sexual partners & 426 & - & $50(11.8)$ \\
\hline Sex for money & 428 & $1(33.3)$ & $13(3.1)$ \\
\hline Used condom always or most of the time & 429 & $1(33.3)$ & $40(9.4)$ \\
\hline Tattoo total & 431 & $1(33.3)$ & $167(39.0)$ \\
\hline Tattoo privately & 422 & $1(50.0)$ & $159(37.9)$ \\
\hline Tattoo parlour & 271 & $1(33.3)$ & $8(3.0)$ \\
\hline Blood transfusion & 417 & & $67(16.2)$ \\
\hline
\end{tabular}

*Median (interquartile range)

much higher than the average prevalence in the Slovak Republic (1.7\%) (13). Altogether almost 53\% had come into contact with hepatitis B virus in the past or present (12.5\% HBsAg positive, and 40.4\% HBsAg negative, but HBcIgG positive). General hepatitis B prevalence in the United States is around $0.3 \%$, but it is much higher in communities of people from South East Asia (Chinese 10\%, Vietnamese 14\%, Laotians 14\%) (14). High hepatitis B prevalence could persist in relatively closed communities because of inadequate anti-epidemiological procedures. Therefore, these communities could be a source of infection for the unvaccinated majority population.

Roma do not constitute a homogenous ethnic group. Spanish authors have compared the prevalence of hepatitis B in two communities (ciganes and gypsies), presumably pertaining to the same ethnic group and considered to have high risk for the disease. Serologic markers were determined in 245 ciganes (65\% of the total of the cigane population) and in 127 gypsies (45\% of the total gypsy population). HBsAg was negative in the gypsies and positive in $27 \%$ of the ciganes. Antibodies were found in $12 \%$ of the gypsies and in $72 \%$ of the ciganes (15).

One possible route of infection is vertical transmission from mother to the child during birth. Hepatitis B prevalence in Roma mothers is a lot higher than in the general population. In the Spanish study the determination of HBsAg in 3,404 pregnant women showed 84 positive cases (2.46\%), which is above the average for the Spanish population. Gypsy women showed a statistically higher rate of chronic HBV infection (8.4\%) than the non-Gypsy population (1.4\%) (16). Slovak authors reported that average hepatitis B prevalence in pregnant women in regions with less than $5 \%$ of Roma population was $0.98 \%$ compared with $2.72 \%$ in regions where Roma accounted for $\geq 5 \%$ of inhabitants (13). 
Horizontal transmission is a second important route of infection in hepatitis B. We found two important facts that support this route of infection in this cohort. First, men constitute 50.9\% of HBsAgpositive and only $30.8 \%$ of HBcIgG-negative participants; and second, HBsAg-positive and HBcIgG-positive participants were significantly older than participants negative for all serological markers of hepatitis B virus infection. Therefore, the high hepatitis B prevalence in Roma communities in eastern Slovakia is probably caused by high intrafamily horizontal transmission in infancy in addition to vertical transmission.

Behavioural factors could play an important role in the high prevalence of chronic active hepatitis B virus infection in Roma. HBsAg-positive participants were twice as often inmates in a correctional facility compared with HBsAg-negative/HBc IgG-negative participants (12.7\% vs. 6.4\%, NS). Anti-HBc IgGpositive but HBsAg-negative participants were significantly more often prison inmates than participants negative for all serological markers of hepatitis B (13.7\% vs. 6.4\%). A higher prevalence of hepatitis B and C among prison inmates compared with the general population has been confirmed in the published literature as well (17).

We have observed an overall trend toward more frequent tattoos among HBsAg-positive participants compared with HBsAg-/ anti-HBc IgG-negative participants (44.2\% vs. 33.7\%, NS). HBsAg-positive patients had also been more frequently tattooed privately, rather than in an official tattoo parlour. HBsAg-/anti$\mathrm{HBc}$ IgG-positive participants had also been significantly more tattooed compared with HBsAg-/anti-HBc IgG-negative participants (44.3\% vs. $33.7 \%)$ and were more often tattooed outside an official tattoo studio (43.6\% vs. 32.3\%). In a meta-analysis performed by Canadian authors, the pooled odds ratios (95\% $\mathrm{CI}$ ) of the association of tattooing and hepatitis B infection was 1.48 (1.30-1.68) (18). Tattooing in the Roma population could be means of hepatitis $\mathrm{B}$ transmission through the use of shared needles (19), especially when the tattoo is performed at home. Unfortunately, the study data does not show either tattooing or intravenous drug use as being significant risk factors for HBsAg positivity.

Sexual intercourse was not proven to be a risk factor in hepatitis $\mathrm{B}$ transmission in this study. We found no significant difference in HBsAg positivity between participants who reported more than 4 sexual partners and participants with 4 or less sexual partners, or participants who reported that they had received money for sexual intercourse. This is probably caused by the data obtaining method. Roma participants provided lifestyle associated data via a structured interview, which probably led to gender-specific under-reporting/over-reporting of the number of sexual partners. Male participants reported having had significantly more sexual partners than women (Fig. 1).

The use of condoms could lower the risk of hepatitis B transmission. Regular use of condom decreased the prevalence of anti-HBc positivity almost three-times (20). Natural condoms allowed leakage of the hepatitis B virus, whereas synthetic condoms prevented leakage of the hepatitis B virus (21). In this study, 20\% of HBsAg-positive participants used condom always or frequently compared with $7.4 \%$ of participants negative for $\mathrm{HBsAg}$ and anti-HBc IgG. This contradiction is probably caused by the low number of participants who reported using condom (41 participants, 9.3\%) and by the fact that participants who reported using condom had significantly more sexual partners (Fig. 2). Out of the participants who reported more than 4 sexual partners, $21.2 \%$ used condom always or frequently, compared with $7.8 \%$ who did not use condom at all. Therefore, it is clear that there is greater promiscuity among Roma participants who use condom frequently and have higher risk of contracting hepatitis B.

Hepatitis B vaccination, if it produces protective titers of antibodies, could significantly lower the prevalence of the disease. In the above-mentioned Greek study the authors found protective titers of anti-HBs antibodies in 14\% of Roma children but in $96 \%$ of children from the majority population (12). Hungarian authors reported that only $6 \%$ of Roma had effective titers of anti-HBs antibodies, compared with $28.6 \%$ of the majority population (11). The compulsory vaccination of newborns in Slovakia was put into effect in 1998 (22). Therefore, participants in this study have not been vaccinated, only a small number (15 participants, 3.3\%) reported having been vaccinated against hepatitis B in adulthood.

The vaccination rate among Italian gypsy children living in Rome was also low. In a short time period during the year 2002, two thousand out of 2,400 13-year old children living in 32 Roma communities were vaccinated (23). Vaccination of the majority of HBsAg and anti-HBc-negative Roma population could stop further spreading of hepatitis B in Roma communities in eastern Slovakia.

Hepatitis C prevalence in this study was very low. We detected anti-HCV antibodies in only $3(0.7 \%)$ Roma participants. Two participants were coinfected with hepatitis $\mathrm{B}$. The prevalence of anti-HCV positivity in the general Slovak population is $1.52 \%$ and half of these patients are HCV RNA positive (24). Hepatitis $\mathrm{C}$ prevalence in the Roma population of the Czech city of Brno was $4.3 \%$, which is almost 20 -times higher than in the general Czech population. Intravenous drug use and former imprisonment were the significant parameters associated with HCV infection. Heroin abuse prevailed over pervitin (methamphetamine) abuse especially in unemployed men under 20 years of age, and heroin abuse was associated with a higher risk of HCV infection than pervitin abuse (25). In this study we found that hepatitis $C$ prevalence in the Roma population is approximately the same as in the general population. In contrast to the Roma community from the Czech study, only $2.1 \%$ of the study participants reported intravenous drug use. Out of 3 anti-HCV positive patients, one had tattoo, one had received blood transfusion and one had more than 4 sexual partners. No anti-HCV positive patients had been in prison and those who were anti-HCV positive were younger (25.5 vs. 35.5 years), however, due to low number of anti-HCV positive participants no relevant analysis could be performed.

\section{CONCLUSION}

Hepatitis B prevalence in the Roma population of eastern Slovakia is very high. Serological markers of active or resolved hepatitis B infection were found in more than half of participants aged 15-45 years. Males and older people were more likely to acquire hepatitis B infection. Imprisonment and a tattoo, particularly one performed at home, were identified as risk factors for hepatitis B infection. The vaccination of the Roma population negative for serological markers of hepatitis B infection is an urgent socioeconomic and medical challenge and was proved 
to be an effective and sustainable model for prevention (26). In contrast to hepatitis $\mathrm{B}$, hepatitis $\mathrm{C}$ prevalence among Roma in eastern Slovakia is relatively low $(0.7 \%)$. We suppose that this is associated with the very rare use of intravenous drugs.

\section{Acknowledgement}

This work was partially supported by the Agency of the Slovak Ministry of Education for the Structural Funds of EU, CEMIO-ITMS: 26220120058 (30\%), the project VEGA grant 1/1072/12, the Visegrad fund, and by Roche Slovakia, s. r. o. This paper was also partially funded within the framework of the project "Social determinants of health in socially and physically disadvantaged and other groups of population" (CZ.1.07/2.3.00/20.0063).

\section{Conflict of Interests}

None declared

\section{APPENDIX}

HepaMeta Team: Peter Jarčuška, Andrea Madarasová Gecková, Mária Mareková, Daniel Pella, Leonard Siegfried, Pavol Jarčuška, Lýdia Pastvová, Ján Fedačko, Jana Kollárová, Peter Kolarčik, Daniela Bobáková, Zuzana Veselská, Ingrid Babinská, Sylvia Dražilová, Jaroslav Rosenberger, Ivan Schréter, Pavol Kristian, Eduard Veselíny, Martin Janičko, Ladislav Virág, Anna Birková, Marta Kmet’ová, Monika Halánová, Darina Petrášová, Katarína Cáriková, Viera Lovayová, Lucia Merkovská, Lucia Jedličková, Ivana Valková

\section{REFERENCES}

1. Husa P. News in treatment of chronic viral hepatitis. Interní Med. 2007;9(5):217-20. (In Czech.)

2. Lok AS, McMahon BJ. Chronic hepatitis B. Hepatology. 2007 Feb;45(2):507-39.

3. Kristian P, Mikas J, Schréter I. Epidemiology of hepatitis C. Trendy Hepatol. 2010;2(1):12-7. (In Slovak.)

4. Alter MJ, Margolis HS. The emergence of hepatitis B as a sexually transmitted disease. Med Clin North Am. 1990 Nov;74(6):1529-41.

5. Wasley A, Grytdal S, Gallagher K; Centers for Disease Control and Prevention (CDC). Surveillance for acute viral hepatitis - United States, 2006. MMWR Surveill Summ. 2008 Mar 21;57(2):1-24.

6. Urbánek P. Hepatitis C virus infection. Prague: Galén; 2004. (In Czech.)

7. Husa P. Viral hepatitis. Prague: Galén; 2005. (In Czech.)

8. Kane M. Global programme for control of hepatitis B infection. Vaccine. 1995;13 Suppl 1:S47-9.
9. Mendizabal I, Lao O, Marigorta UM, Wollstein A, Gusmão L, Ferak V, et al. Reconstructing the population history of European Romani from genome-wide data. Curr Biol. 2012 Dec 18;22(24):2342-9.

10. Madarasová Gecková A, Jarčuška P, Mareková M, Pella D, Siegfried L, Jarčuška P, et al.; HepaMeta Team. HepaMeta - Prevalence of hepatitis $\mathrm{B} / \mathrm{C}$ and metabolic syndrome in population living in separated and segregated Roma settlements: a methodology for a cross-sectional populationbased study using community-based approach. Cent Eur J Public Health. 2014 Mar;22 Suppl:S6-11.

11. Gyarmathy VA, Ujhelyi E, Neaigus A. HIV and selected blood-borne and sexually transmitted infections in a predominantly Roma (Gypsy) neighbourhood in Budapest, Hungary: a rapid assessment. Cent Eur J Public Health. 2008 Sep;16(3):124-7.

12. Michos A, Terzidis A, Kalampoki V, Pantelakis K, Spanos T, Petridou ET. Seroprevalence and risk factors for hepatitis A, B, and C among Roma and non-Roma children in a deprived area of Athens, Greece. J Med Virol. 2008 May;80(5):791-7.

13. Kristian P, Dankulincová Veselská Z, Paraličová Z, Jarčuška P, Virág L, Valková I, et al. Regional and ethnic aspects of viral hepatitis B among pregnant women. Cent Eur J Public Health. 2013 Mar;21(1):22-5.

14. Do S. The natural history of hepatitis B in Asian Americans. Asian Am Pac Isl J Health. 2001 Summer-Fall;9(2):141-53.

15. Virto Ruiz MT, Marín Alcalá MPL, Pascual Val T, López Morrás C, Aramburu Bergua I, Zubicoa Ventura J. Endemic hepatitis B in 2 marginal ethnic minorities. Comparative study. Med Clin (Barc). 1993 Sep 11;101(7):245-8. (In Spanish.)

16. Cruz M, Dieguez A, Fos E, Hierro F. Epidemiologic survey on hepatitis B in Gypsy women. Eur J Epidemiol. 1988 Sep;4(3):314-7.

17. Kirwan P, Evans B; Sentinel Surveillance of Hepatitis Testing Study Group, Brant L. Hepatitis C and B testing in English prisons is low but increasing. J Public Health (Oxf). 2011 Jun;33(2):197-204.

18. Jafari S, Buxton JA, Afshar K, Copes R, Baharlou S. Tattooing and risk of hepatitis B: a systematic review and meta-analysis. Can J Public Health. 2012 May-Jun;103(3):207-12.

19. Rosario Pac M, Arnedo A, Montaner MD, Prieto P, García J, Izuel M, et al. Epidemic outbreak of hepatitis B from the tattoo in gypsy families. Rev Esp Salud Publica. 1996 Jan-Feb;70(1):63-9. (In Spanish.)

20. Bernabe-Ortiz A, Carcamo CP, Scott JD, Hughes JP, Garcia PJ, Holmes $\mathrm{KK}$. HBV infection in relation to consistent condom use: a populationbased study in Peru. PLoS One. 2011;6(9):e24721.

21. Minuk GY, Bohme CE, Bowen TJ, Hoar DI, Cassol S, Gill MJ, et al. Efficacy of commercial condoms in the prevention of hepatitis B virus infection. Gastroenterology. 1987 Oct;93(4):710-4.

22. Kristian P, Schréter I. Epidemiology of hepatitis B in the world and in Slovakia. Trendy Hepatol. 2009;1(2):4-7. (In Slovak.)

23. Baglio G, Cacciani L, Napoli PA, Geraci S, Motta F, Ros R. A vaccination campaign for gypsy children in Rome. Ann Ig. 2005 MayJun;17(3):197-207. (In Italian.)

24. Schréter I, Kristian P, Klement C, Kohútová D, Jarčuška P, Mad’arová L, et al. Prevalence of hepatitis C virus infection in Slovakia. Klin Mikrobiol Infekc Lek. 2007 Apr;13(2):54-8. (In Slovak.)

25. Husa P, Ovesná P. Prevalence and risk factors of hepatitis C in Roma people in Brno. Klin Mikrobiol Infekc Lek. 2011 Dec;17(6):201-7. (In Czech.) 